Gut and Liver, Vol. 10, No. 5, September 2016, pp. 818-825

\title{
Relationship between 25-Hydroxyvitamin D Levels and Liver Fibrosis as Assessed by Transient Elastography in Patients with Chronic Liver Disease
}

Bong Jin $\mathrm{Ko}^{1}$, Young Seok Kim${ }^{1}$, Sang Gyune $\mathrm{Kim}^{1}$, Jung Hwan Park ${ }^{1}$, Sae Hwan Lee ${ }^{2}$, Soung Won Jeong ${ }^{3}$, Jae Young Jang ${ }^{3}$, Hong Soo Kim ${ }^{2}$, Boo Sung Kim${ }^{1}$, Sun Mi Kim${ }^{1}$, Young Don Kim ${ }^{4}$, Gab Jin Cheon ${ }^{4}$, and Bo Ra Lee ${ }^{5}$

${ }^{\prime}$ Digestive Disease Center and Research Institute, Department of Internal Medicine, Soonchunhyang University Bucheon Hospital, Soonchunhyang University College of Medicine, Bucheon, ${ }^{2}$ Department of Internal Medicine, Soonchunhyang University Cheonan Hospital, Soonchunhyang University College of Medicine, Cheonan, ${ }^{3}$ Department of Internal Medicine, Soonchunhyang University Seoul Hospital, Soonchunhyang University College of Medicine, Seoul, ${ }^{4}$ Department of Internal Medicine, Gangneung Asan Hospital, University of Ulsan College of Medicine, Gangneung, and ${ }^{5}$ Department of Biostatistical Consulting, Soonchunhyang University Bucheon Hospital, Bucheon, Korea

Background/Aims: Deficiencies of 25-hydroxyvitamin D $(25(\mathrm{OH}) \mathrm{D})$ are prevalent in patients with chronic liver disease (CLD). Liver fibrosis is the main determinant of CLD prognosis. The present study was performed to evaluate the correlation between 25(OH)D levels and liver fibrosis as assessed by transient elastography (TE) in patients with compensated CLD. Methods: Serum 25(OH)D levels and liver stiffness were determined in a total of 207 patients who were subjected to the following exclusion criteria: patients with decompensated CLD; patients who had malignancies; patients who were taking medications; and patients who were pregnant. Results: The most common etiology was chronic hepatitis $B$ (53.1\%). Advanced liver fibrosis (defined by TE [ $\geq 9.5 \mathrm{kPa}]$ ) was present in 75 patients (36.2\%). There was a significant correlation between 25(OH)D deficiency and liver stiffness. Based on the multivariate analysis, the following factors were independently associated with advanced liver fibrosis: 25(OH)D deficiency (odds ratio [OR], 3.46; $p=0.004$ ), diabetes mellitus (OR, 3.04; $p=0.041)$, and fibrosis-4 index (OR, 2.01; $p<0.001)$. Conclusions: Patients with compensated CLD exhibit a close correlation between vitamin D level and liver stiffness as assessed by TE. Vitamin D deficiency was independently associated with advanced liver fibrosis. (Gut Liver 2016;10:818-825)

Key Words: 25-Hydroxyvitamin D deficiency; Transient elastography; Liver stiffness

\section{INTRODUCTION}

The classic role of vitamin D involves regulation of calcium and bone metabolism. In recent years, other roles of vitamin D have been elucidated by the nonskeletal effects of this vitamin associated with chronic disease. ${ }^{1}$ Vitamin D deficiency is highly prevalent in patients with chronic liver disease (CLD) regardless of the etiology ${ }^{2}$ and is known to be associated with liver dysfunction and mortality. ${ }^{3}$ Vitamin D plays an important role in the progression of fibrosis and the inflammatory response. ${ }^{4}$ Previous experimental studies indicated that vitamin D can reduce collagen expression and profibrotic factors as well as having immunomodulatory effects on immune cells, including T lymphocytes. ${ }^{5}$ A recent study revealed an antifibrotic effects of vitamin D on human primary transforming growth factor- $\beta$ stimulated hepatic stellate cells. ${ }^{6}$

Liver fibrosis is the main determinant of the prognosis of CLD. ${ }^{7}$ Therefore, accurate assessment of the degree of fibrosis is an important factor for determining the prognosis and establishing a therapeutic strategy in patients with CLD. Although liver biopsy is the gold standard for evaluation of liver fibrosis, it is invasive and is associated with rare but potentially life-threatening complications. In addition, the accuracy of liver biopsy is questionable because of sampling error and poor interobserver reproducibility. ${ }^{8}$

Transient elastography (TE) is a promising noninvasive method of measuring liver fibrosis. The main advantage of TE is that reproducible information can be obtained rapidly from a much larger portion of the liver. ${ }^{9}$ TE shows good performance

\footnotetext{
Correspondence to: Young Seok Kim

Digestive Disease Center and Research Institute, Department of Internal Medicine, Soonchunhyang University Bucheon Hospital, 170 Jomaru-ro, Wonmi-gu, Bucheon 14584, Korea

Tel: +82-32-621-5079, Fax: +82-32-621-5018, E-mail: dr.yskim@gmail.com

Received on July 17, 2015. Revised on September 28, 2015. Accepted on December 1, 2015. Published online April 28,2016 pISSN 1976-2283 eISSN 2005-1212 http://dx.doi.org/10.5009/gnl15331

@ This is an Open Access article distributed under the terms of the Creative Commons Attribution Non-Commercial License (http://creativecommons.org/licenses/by-nc/4.0) which permits unrestricted non-commercial use, distribution, and reproduction in any medium, provided the original work is properly cited.
} 
in evaluating the longitudinal response to antiviral treatment in patients with chronic hepatitis $\mathrm{C}$ virus (HCV) and chronic hepatitis B virus (HBV) infection, ${ }^{10}$ and it has been shown to be clinically useful in patients with alcoholic liver disease. ${ }^{11}$

The relationship between liver fibrosis and the vitamin D level in patients with chronic HCV infection has been widely observed in many studies. ${ }^{12-15}$ However, this relationship in patients with liver disease of etiologies other than chronic HCV infection is less clear. Grünhage et al. ${ }^{16}$ evaluated liver disease of various etiologies, and Efe et al. ${ }^{17}$ evaluated autoimmune liver disease, with regard to the inverse relationship between serum vitamin D level and liver fibrosis. Although the study of Grünhage et al. ${ }^{16}$ included various etiologies, most patients had chronic HCV infection (60.8\%), and all patients were of Caucasian ethnicity.

In this study, we evaluated the correlation between the 25-hydroxyvitamin D (25(OH)D) level and liver fibrosis using TE in Korean patients with CLD.

\section{MATERIALS AND METHODS}

\section{Patients}

We performed a retrospective analysis of prospectively collected data from all patients with CLD who underwent TE and measurement of serum 25(OH)D level at intervals of $<3$ months at the outpatient clinic of Soonchunhyang University Hospital, Bucheon, Korea, from January 2013 to June 2014.

A total of 260 patients were enrolled in this study. Patients were excluded from the present analysis if they had decompensated liver cirrhosis, a malignant disease (including hepatocellular carcinoma) or medications known to affect vitamin D metabolism, including vitamin or mineral supplements (calcium, vitamin $\mathrm{D}$, or hormonal therapy), or pregnancy. Cirrhosis was diagnosed on the basis of clinical and radiological features or liver histology. ${ }^{18}$ Decompensated liver cirrhosis was considered present when ascites, hepatic encephalopathy, hepatorenal syndrome, and/or esophageal variceal bleeding, were/was evident. After exclusion of these patients, a total of 207 patients were included in the analysis.

In addition to epidemiological data, the following biological parameters of all patients were evaluated at the time of liver stiffness (LS) measurement: serum aspartate aminotransferase (AST) level, serum alanine aminotransferase (ALT) level, creatinine level, platelet count, albumin level, total bilirubin level, $\gamma$-glutamyl transpeptidase (GGT) level, basal insulin level, and fasting glucose level. The AST/platelet ratio index (APRI) was calculated as follows: [(AST/upper limit of normal with normal considered as $40 \mathrm{IU} / \mathrm{L} /$ platelet count $\left.\left.\times 10^{9} / \mathrm{L}\right) \times 100\right] .^{19}$ The fibrosis-4 index (FIB-4) was calculated as follows: (agexAST)/(platelet count $\times$ root ALT). ${ }^{20}$ The basal insulin and fasting glucose levels were calculated with the homeostasis model for assessmentinsulin resistance (HOMA-IR) as follows: fasting blood glucose (mg/dL) xfasting insulin/405. The cause of CLD was determined using standard diagnostic criteria. HCV or HBV infection was diagnosed by serological detection of HCV antibodies and HBV surface antigen, respectively. ${ }^{21,22}$ Alcoholic liver disease was defined as a disease associated with consumption of $\geq 40 \mathrm{~g}$ alcohol daily for $\geq 5$ years. ${ }^{23}$ Other diseases were diagnosed using currently recognized criteria. ${ }^{24,25}$

This study was performed in accordance with the ethical guidelines of the 1975 Declaration of Helsinki and was approved by the Institutional Review Board of Soonchunhyang University Hospital.

\section{Assessment of serum 25(OH)D level}

The serum 25(OH)D level was analyzed by isotope-dilution liquid chromatography-tandem mass spectrometry. The vitamin D status was defined according to the following 25(OH)D levels: deficiency, $<10 \mathrm{ng} / \mathrm{mL}$; insufficiency, $<20 \mathrm{ng} / \mathrm{mL}$; and sufficiency, $\geq 20 \mathrm{ng} / \mathrm{mL}{ }^{26}$

\section{Liver stiffness measurement}

LS values were measured by a single experienced technician (>5,000 examinations) using a TE device (FibroScan ${ }^{\circledR}$; Echosens, Paris, France) according to previously described methods. ${ }^{27}$ The results are expressed as kilopascals $(\mathrm{kPa})$. The interquartile

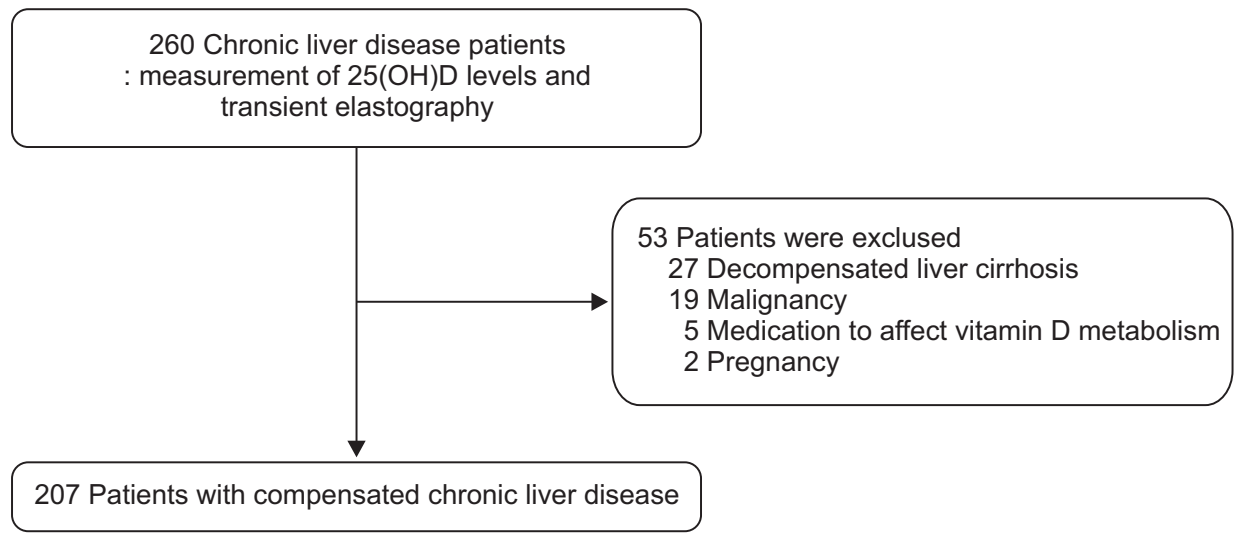

Fig. 1. Patient enrollment. In total, 260 patients with chronic liver disease underwent 25-hydroxyvitamin D (25(OH)D) level measurements and transient elastography. Fiftythree patients were excluded because they met the exclusion criteria. Thus, 207 patients were enrolled for the statistical analysis. 
range (IQR) was defined as the index of intrinsic variability of LS values corresponding to the interval of LS results containing 50\% of the valid measurements between the 25th and 75th percentiles. In the present study, LS values with $\geq 10$ validated measurements and an IQR-to-median-value ratio (IQR/M) of $<0.3$ were considered reliable. The fibrosis stage was defined according to the LS score as measured by TE: no or minimal fibrosis (Equivalent to Metavir F0-F1), $<7.1 \mathrm{kPa}$; moderate fibrosis (F2), 7.1 to $9.4 \mathrm{kPa}$; severe fibrosis $(\geq \mathrm{F} 3), \geq 9.5 \mathrm{kPa} .{ }^{9}$ Moreover, advanced liver fibrosis $(\geq F 3)$ was defined as a fibrosis score of $>9.5 \mathrm{kPa}$.

\section{Statistical analyses}

Statistical analysis was performed using SPSS version 18.0
(SPSS Inc., Chicago, IL, USA). Normally distributed continuous variables are expressed as the means \pm standard deviation, skewdistributed continuous variables are expressed as the median (IQR), and categorical variables are expressed as the number and percentage. Fisher exact test or the chi-squared test was used to compare categorical variables. Differences between continuous variables were examined with Student t-test or the MannWhitney U test, as appropriate. Correlations were tested with Spearman correlation coefficient. Comparison of LS among different vitamin D statuses was performed using the KruskalWallis test. Univariate and multivariate logistic regression analyses with backward elimination were used to investigate factors associated with advanced liver fibrosis (TE $\geq 9.5 \mathrm{kPa}$ ). We also assessed the association between vitamin $\mathrm{D}$ concentration

Table 1. Patient's Characteristics

\begin{tabular}{|c|c|c|c|}
\hline Characteristic & No advanced fibrosis $(n=132)$ & Advanced fibrosis $(n=75)$ & Total $(n=207)$ \\
\hline Age, yr & $46 \pm 11$ & $51 \pm 10$ & $48 \pm 11$ \\
\hline Male sex & $99(75)$ & $52(69.3)$ & $151(72.9)$ \\
\hline Hypertension & $17(12.9)$ & $11(14.7)$ & $28(13.5)$ \\
\hline Diabetes mellitus & $13(9.8)$ & $23(30.7)$ & $36(17.4)$ \\
\hline Body mass index, $\mathrm{kg} / \mathrm{m}^{2}$ & $24.15 \pm 3.5$ & $23.6 \pm 3.9$ & $23.9 \pm 3.6$ \\
\hline \multicolumn{4}{|l|}{ Etiology } \\
\hline $\mathrm{CHB}^{*}$ & $83(62.9)$ & $27(36)$ & $110(53.1)$ \\
\hline $\mathrm{CHC}^{\dagger}$ & $8(6.1)$ & $7(9.3)$ & $15(7.3)$ \\
\hline NAFLD $^{\ddagger}$ & 18 (13.6) & $7(9.3)$ & $25(12.1)$ \\
\hline Alcohol & $14(10.6)$ & $27(36)$ & 41 (19.8) \\
\hline Others & $9(6.8)$ & $7(9.3)$ & $16(7.7)$ \\
\hline \multicolumn{4}{|l|}{ Sample season } \\
\hline Spring-summer & $75(56.8)$ & $38(50.7)$ & $113(54.6)$ \\
\hline AST, IU/L & $34.33 \pm 25.8$ & $56.16 \pm 42.43$ & $42.24 \pm 34.36$ \\
\hline ALT, IU/L & $40.16 \pm 38.53$ & $41.95 \pm 41.41$ & $40.81 \pm 39.5$ \\
\hline Serum creatinine, $\mathrm{mg} / \mathrm{dL}$ & $1.09 \pm 0.9$ & $0.92 \pm 0.18$ & $1.0 \pm 0.7$ \\
\hline Platelet count, $\times 10^{9} / \mathrm{L}$ & $225.1 \pm 77.1$ & $178.7 \pm 89.2$ & $203.5 \pm 82.2$ \\
\hline Serum albumin, g/dL & $4.38 \pm 0.4$ & $3.97 \pm 0.62$ & $4.2 \pm 0.5$ \\
\hline Total bilirubin, mg/dL & $0.77 \pm 0.28$ & $1.45 \pm 1.62$ & $1.02 \pm 1.05$ \\
\hline GGT, IU/L & $61.9 \pm 78.5$ & $228.4 \pm 361.4$ & $122.9 \pm 240.2$ \\
\hline FIB4 & $1.1(0.7-1.6)$ & $2.6(1.4-4.2)$ & $1.4(0.9-2.7)$ \\
\hline APRI & $0.3(0.2-0.5)$ & $0.7(0.4-1.3)$ & $0.4(0.2-0.8)$ \\
\hline HOMA-IR & $2.7(1.8-3.8)$ & $3.9(2.3-6.0)$ & $2.8(1.8-4.4)$ \\
\hline \multicolumn{4}{|l|}{ Vitamin D status } \\
\hline 25(OH)D deficiency & $32(24.2)$ & $40(53.3)$ & $72(34.8)$ \\
\hline 25(OH)D insufficiency & $70(53.0)$ & $24(32.0)$ & $94(45.4)$ \\
\hline 25(OH)D sufficiency & $30(22.8)$ & $11(14.7)$ & $41(19.8)$ \\
\hline Child-Pugh score & 5 (123), 6 (7), 7 (2) & 5 (50), 6 (11), 7 (9), 8 (5) & 5 (173), 6 (18), 7 (11), 8 (5) \\
\hline
\end{tabular}

Data are presented as mean $\pm \mathrm{SD}$, number (\%), or median (interquartile range).

CHB, chronic hepatitis B virus; CHC, chronic hepatitis C; NAFLD, nonalcoholic fatty liver disease; AST, aspartate aminotransferase; ALT, alanine aminotransferase; GGT, $\gamma$-glutamyl transpeptidase; FIB4, fibrosis 4 score; APRI, AST/platelet ratio index score; HOMA-IR, homeostasis model for assessment-insulin resistance. 
and seasonal timing of sampling to evaluate the general influence of sun exposure on vitamin D level (April to September vs October to March). In all analyses, p-value $<0.05$ was taken to indicate statistical significance.

\section{RESULTS}

\section{Patient characteristics}

The 25(OH)D level and LS value determined by TE were measured in 260 patients with CLD. Fifty-three patients were excluded because they met the exclusion criteria; 27 patients had decompensated liver cirrhosis, 19 had malignant disease, five were taking a medication that affected vitamin D metabolism, and two were pregnant. Of the 27 patients excluded due to decompensated liver cirrhosis, all exhibited ascites; one had hepatic encephalopathy, six had no evidence of esophageal varices, and eight had endoscopic varices of grade I, eight varices of grade II, and five varices of grade III. Finally, 207 patients were included in the study (Fig. 1).

The patients' characteristics are summarized in Table 1 . The mean age of the patients was 48 years old, 151 were men, and 56 were women. Twenty-eight patients had hypertension as a comorbidity, and 36 had diabetes mellitus (DM). About 60\% of patients had chronic HBV or HCV infection. Other causes included nonalcoholic fatty liver disease (NAFLD) $(n=25)$, alcoholic liver disease $(n=41)$, and other conditions ( $n=16$; autoimmune disease in 4 , primary biliary cirrhosis in 3 , toxicity in 3 , and cryptogenic liver disease in 6). All patients had well-preserved liver function. The mean AST level was 42.2 IU/L, ALT level was $40.8 \mathrm{IU} / \mathrm{L}$, serum creatinine level was $1.0 \mathrm{mg} / \mathrm{dL}$, platelet count was $203.5 \times 10^{9} / \mathrm{L}$, serum albumin level was $4.2 \mathrm{~g} / \mathrm{dL}$, and total bilirubin level was $1.02 \mathrm{mg} / \mathrm{dL}$. The median serum 25(OH) D level was $12.7 \mathrm{ng} / \mathrm{mL}$ (IQR, 9.0 to $18.6 \mathrm{ng} / \mathrm{mL}$ ). A total of 94 (45\%) patients had vitamin D insufficiency defined as a serum 25(OH)D level of 10 to $20 \mathrm{ng} / \mathrm{mL}$, and 72 (34\%) had vitamin D deficiency defined as a serum 25(OH)D level $<10 \mathrm{ng} / \mathrm{mL}$. The median LS determined by TE was $6.8 \mathrm{kPa}$ (IQR, 5.0 to $11.5 \mathrm{kPa}$ ). In total, 107 (51.7\%) patients had minimal fibrosis $(<7.1 \mathrm{kPa})$, 25 had moderate fibrosis $(\geq 7.1$ to $<9.5 \mathrm{kPa}$ ), and 75 had severe fibrosis ( $\geq 9.5 \mathrm{kPa}$ ). The mean Child-Pugh score was 5.27 . The vitamin D level and LS showed a significant inverse correlation $(\mathrm{r}=-0.190, \mathrm{p}=0.006)$.

\section{Comparison of patients by vitamin $D$ status $(<10 \mathrm{ng} / \mathrm{mL}$ vs $\geq 10 \mathrm{ng} / \mathrm{mL}$ )}

Fig. 2 shows the distribution of LS values according to the vitamin D status. There were significant differences among the deficiency, insufficiency, and sufficiency groups ( $p=0.001)$. In the vitamin D deficiency group $(<10 \mathrm{ng} / \mathrm{mL})$, the LS value was significantly different from those in the sufficiency $(\geq 20 \mathrm{ng} / \mathrm{mL}$ ) and insufficiency groups $(<20 \mathrm{ng} / \mathrm{mL})$. However, we found no differences between the sufficiency and insufficiency groups.
Patient characteristics according to the 25(OH)D levels ( $<10 \mathrm{ng} /$ $\mathrm{mL}$ vs $\geq 10 \mathrm{ng} / \mathrm{mL}$ ) are summarized in Table 2. No associations were observed between the 25(OH)D level and age, sex, comorbidities (hypertension and DM), body mass index (BMI), or etiology of liver disease. Similarly, no significant associations were observed between the 25(OH)D level and the AST level, ALT level, creatinine level, or platelet count. However, the serum albumin level $(\mathrm{p}<0.001)$, total bilirubin level $(\mathrm{p}=0.02)$, GGT level $(p=0.044)$, and FIB-4 ( $p=0.048)$ were significantly associated with 25(OH)D deficiency. APRI and HOMA-IR were not associated with 25(OH)D $<10 \mathrm{ng} / \mathrm{mL}$. As expected, 25(OH)D deficiency was strongly associated with LS ( $\mathrm{p}<0.001)$. Notably, seasonal timing of sampling for 25(OH)D measurement during spring to summer was linked to a higher 25(OH)D level than those during autumn and winter $(\mathrm{p}=0.019)$.

\section{Univariate and multivariate analyses of factors associ- ated with LS ( $\geq 9.5 \mathrm{kPa}$ )}

Age, DM, AST level, GGT level, total bilirubin level, platelet count, albumin level, FIB-4, and APRI score were selected as significant factors associated with severe liver fibrosis (Table 3). In multivariate analysis, vitamin D deficiency was significantly associated with severe liver fibrosis (odds ratio [OR], 3.46; 95\% confidence interval [CI], 1.47 to $8.14 ; \mathrm{p}<0.001$ ) (Table 3) independent of other factors (age, DM, AST level, GGT level, total bilirubin level, albumin level, FIB-4, and APRI) and seasonal timing of sampling. In addition, there were significant associations between severe liver fibrosis and DM (OR, 3.04; 95\% CI, 1.05 to $8.83 ; \mathrm{p}=0.041$ ) (Table 3 ) and the FIB-4 (OR, 2.01; 95\%

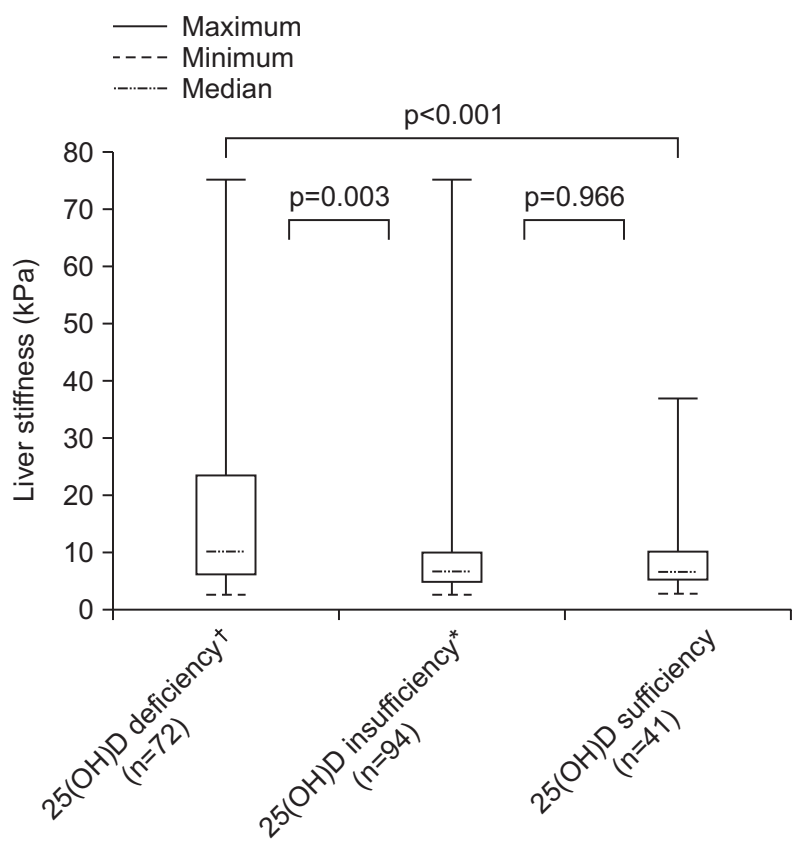

Fig. 2. Distribution of liver stiffness values according to vitamin $D$ status. ${ }^{*} 25(\mathrm{OH}) \mathrm{D}<20 \mathrm{ng} / \mathrm{mL} ;{ }^{\dagger} 25(\mathrm{OH}) \mathrm{D}<10 \mathrm{ng} / \mathrm{mL}$. 
Table 2. Comparison of Patients according to Their Vitamin D Status ( $<10 \mathrm{ng} / \mathrm{mL}$ vs $\geq 10 \mathrm{ng} / \mathrm{mL})$

\begin{tabular}{|c|c|c|c|}
\hline & \multicolumn{2}{|c|}{ 25(OH)D } & \multirow{2}{*}{$\mathrm{p}$-value } \\
\hline & $<10 \mathrm{ng} / \mathrm{mL}(\mathrm{n}=72)$ & $\geq 10 \mathrm{ng} / \mathrm{mL}(\mathrm{n}=135)$ & \\
\hline Age, yr & $49.7 \pm 11.4$ & $46.8 \pm 10.7$ & 0.070 \\
\hline Male sex & $53(73.6)$ & $98(72.5)$ & 0.875 \\
\hline Hypertension & $6(8.3)$ & $22(16.2)$ & 0.137 \\
\hline Diabetes mellitus & $17(23.6)$ & $19(14)$ & 0.085 \\
\hline Body mass index, $\mathrm{kg} / \mathrm{m}^{2}$ & $23.4 \pm 11.4$ & $24.2 \pm 3.5$ & 0.173 \\
\hline Etiology & & & 0.184 \\
\hline $\mathrm{CHB}$ & $34(47.2)$ & $76(56.3)$ & \\
\hline $\mathrm{CHC}$ & $8(11.1)$ & $7(5.2)$ & \\
\hline NAFLD & $6(8.4)$ & $19(14.1)$ & \\
\hline Alcohol & $16(22.2)$ & $25(18.5)$ & \\
\hline Others & $8(11.1)$ & $8(5.9)$ & \\
\hline \multicolumn{4}{|l|}{ Sample season } \\
\hline Spring-summer & $31(43)$ & $82(60.7)$ & 0.019 \\
\hline AST, IU/L & $47.4 \pm 39.3$ & $39.5 \pm 31.2$ & 0.116 \\
\hline ALT, IU/L & $38.4 \pm 31.0$ & $42.8 \pm 43.4$ & 0.529 \\
\hline Serum creatinine, $\mathrm{mg} / \mathrm{dL}$ & $0.95 \pm 0.17$ & $1.07 \pm 0.93$ & 0.298 \\
\hline Platelet count, $\times 10^{9} / \mathrm{L}$ & $200.9 \pm 99.2$ & $210.6 \pm 75$ & 0.457 \\
\hline Serum albumin, g/dL & $3.9 \pm 0.6$ & $4.35 \pm 0.4$ & $<0.001$ \\
\hline Total bilirubin, mg/dL & $1.31 \pm 1.6$ & $0.86 \pm 0.5$ & 0.020 \\
\hline GGT, IU/L & $69(27-148)$ & $43(24-89.5)$ & 0.034 \\
\hline Creatinine clearance & $88.9 \pm 25.1$ & $85.9 \pm 24.7$ & 0.415 \\
\hline Serum calcium & $8.9 \pm 0.48$ & $9.05 \pm 0.62$ & 0.301 \\
\hline Serum phosphate & $3.4 \pm 0.84$ & $3.4 \pm 0.74$ & 0.888 \\
\hline APRI & $0.48(0.3-0.92)$ & $0.36(0.25-0.67)$ & 0.069 \\
\hline HOMA-IR & $3.11(1.77-5.7)$ & $2.81(1.97-4.32)$ & 0.464 \\
\hline Liver stiffness, $\mathrm{kPa}$ & $10.0(5.85-23.45)$ & $6.3(4.7-9.7)$ & $<0.001$ \\
\hline Child-Pugh score & $5.54 \pm 0.91$ & $5.12 \pm 0.48$ & 0.001 \\
\hline
\end{tabular}

Data are presented as mean $\pm \mathrm{SD}$, number (\%), or median (interquartile range).

CHB, chronic hepatitis B; CHC, chronic hepatitis C; NAFLD, nonalcoholic fatty liver disease; AST, aspartate aminotransferase; ALT, alanine aminotransferase; GGT, $\gamma$-glutamyl transpeptidase; APRI, AST/platelet ratio index score; HOMA-IR, homeostasis model for assessment-insulin resistance.

\section{CI, 1.42 to $2.83 ; \mathrm{p}<0.001$ ) (Table 3 ).}

\section{DISCUSSION}

In this study, we clarified the correlation between the vitamin D level and LS as measured by TE. Moreover, vitamin D deficiency was an independent factor associated advanced liver fibrosis as measured by TE in patients with compensated CLD.

The vitamin D level and LS showed an inverse correlation $(r=-0.190, p=0006)$ similar to that described previously in a German cohort $(\mathrm{r}=-0.267, \mathrm{p}<0.001) .{ }^{16}$ The LS value in the vitamin $\mathrm{D}$ deficiency group was significantly higher than those in the other two groups, but there was no difference in LS between the vitamin D insufficiency and sufficiency groups. DM, insulin resistance, and obesity are known to be associated with vita- min D deficiency. ${ }^{28,29}$ In the present study, we found that these conditions were commonly associated with NAFLD. Also, BMI, HOMA-IR, and prevalence of DM were not significantly different between patients with vitamin D levels of $<10$ and $\geq 10 \mathrm{ng} /$ $\mathrm{mL}$. Therefore, it is likely that these results were largely attributable to the small proportion of patients with NAFLD (14\%) in our cohort. Rode et $a l^{30}$ found that that the vitamin D level correlated with that of albumin. In our present study, the serum albumin level was also significantly associated with vitamin D deficiency. Of all patients, $17.5 \%$ had DM; this proportion is higher than that in the normal populations. In a Japanese study, the proportion of HCV patients with DM was 20.9\% and that of HBV patients $11.9 \% .^{31}$ The incidence of DM in patients with non-alcoholic fatty liver disease was $17.4 \% .^{32}$ The higher proportion of DM patients (compared with that in the normal 
Table 3. Factors Associated with Advanced Liver Fibrosis (TE $\geq 9.5 \mathrm{kPa}$ )

\begin{tabular}{|c|c|c|c|c|c|c|}
\hline \multirow{2}{*}{ Variable } & \multicolumn{3}{|c|}{ Univariate } & \multicolumn{3}{|c|}{ Multivariate } \\
\hline & OR & $95 \% \mathrm{CI}$ & p-value & $\mathrm{OR}$ & $95 \% \mathrm{CI}$ & $\mathrm{p}$-value \\
\hline Age, yr & 1.04 & $1.01-1.07$ & 0.003 & & & \\
\hline Female sex & 1.32 & $0.70-2.49$ & 0.378 & & & \\
\hline Body mass index & 0.95 & $0.88-1.03$ & 0.290 & & & \\
\hline Hypertension & 1.16 & $0.51-2.63$ & 0.718 & & & \\
\hline Diabetes mellitus & 4.04 & $1.90-8.60$ & $<0.001$ & 3.04 & $1.05-8.83$ & 0.041 \\
\hline \multicolumn{7}{|l|}{ Sample season } \\
\hline Autumn-winter & 1.28 & $0.72-2.26$ & 0.393 & & & \\
\hline $25(\mathrm{OH}) \mathrm{D},<10 \mathrm{ng} / \mathrm{mL}$ & 3.57 & $1.95-6.53$ & $<0.001$ & 3.46 & $1.47-8.14$ & 0.004 \\
\hline AST, IU/L & 1.02 & $1.01-1.03$ & $<0.001$ & & & \\
\hline ALT, IU/L & 1.01 & $0.99-1.01$ & 0.754 & & & \\
\hline GGT, IU/L & 1.01 & $1.00-1.01$ & 0.001 & 1.01 & $1.00-1.01$ & 0.054 \\
\hline Total bilirubin, $\mathrm{mg} / \mathrm{dL}$ & 3.99 & $1.91-8.35$ & $<0.001$ & 2.75 & $0.86-8.81$ & 0.089 \\
\hline Platelet count, $\times 10^{9} / \mathrm{L}$ & 0.99 & $0.99-1.00$ & 0.001 & & & \\
\hline Albumin, g/dL & 0.17 & $0.09-0.33$ & $<0.001$ & & & \\
\hline HOMA-IR & 1.06 & $0.99-1.13$ & 0.112 & & & \\
\hline FIB4 & 1.96 & $1.49-2.58$ & $<0.001$ & 2.01 & $1.42-2.83$ & $<0.001$ \\
\hline APRI & 4.53 & $2.28-8.96$ & $<0.001$ & & & \\
\hline Child-Pugh score & 3.78 & $2.05-6.96$ & $<0.001$ & & & \\
\hline Creatinine clearance & 0.99 & $0.98-1.01$ & 0.859 & & & \\
\hline
\end{tabular}

OR, odds ratio; CI, confidence interval; AST, aspartate aminotransferase; ALT, alanine aminotransferase; GGT, $\gamma$-glutamyl transpeptidase; HOMAIR, homeostasis model for assessment-insulin resistance; FIB4, fibrosis 4 score; APRI, AST/platelet ratio index score.

population) in the present study is explained by the fact that we included patients with diseases of various etiologies and those with compensated liver cirrhosis. Also, the work was performed in a tertiary hospital. This means that the proportion of patients with comorbidities such as DM was greater than that of patients visiting lower-tier clinics.

In this study, we used univariate and multivariate logistic regression analyses of the factors associated with advanced liver fibrosis on TE in patients with compensated CLD. After adjustment for the sampling timing, vitamin D deficiency was an independent factor associated with advanced liver fibrosis. Some studies have shown a correlation between vitamin D level and liver fibrosis. ${ }^{14,17,33}$ These studies were based on liver biopsy. However, in addition to their small number, studies based on TE also lack cohorts with liver disease of various etiologies and Asian patients. ${ }^{13,16}$ This is the first study to assess the factors associated with advanced liver fibrosis by TE in various etiologies and Asian patients. Recent studies have suggested that DM is an independent factor for liver mortality and complications and leads to the progression of LS in patients with chronic HBV infection. ${ }^{34,35}$ Similar to previous studies, we found that DM was an independent factor of advanced liver fibrosis. FIB-4 and APRI were initially used in Western populations with viral HCV infection and exhibited good performance. ${ }^{36}$ Consequently, these markers have been widely used for assessment of HBVinfected patients. We found that only FIB-4 was associated with advanced liver fibrosis. FIB-4 was reported previously to be more accurate for predicting liver fibrosis than APRI in patients with chronic HBV infection. ${ }^{37}$ It is likely that these results could be largely attributed to chronic HBV infection, the main etiology in our cohort.

Since the first description of TE in $2003,{ }^{27}$ the clinical utility thereof has been evaluated in a number of studies. ${ }^{9,11,38,39}$ Most of these were cross-sectional studies assessing the diagnostic accuracy of TE in evaluation of liver fibrosis in various etiologies of CLD. ${ }^{40}$ In a recent longitudinal study, TE was used to monitor disease progression. ${ }^{41,42}$ LS measurements by TE are difficult when the intercostal spaces are narrow, in obese patients, and in the presence of ascites. The most important environmental factors in vitamin D synthesis are sunlight exposure ${ }^{43}$ and, to a much lower extent, diet and vitamin D dietary supplements. Information on the patients' dietary status was not collected in our study. However, the major source of vitamin D synthesis is derived from the skin through sunlight exposure. Seasonal timing of the sampling also had a significant influence on the vitamin D status in our study. Therefore, we adjusted vitamin $\mathrm{D}$ deficiency with the seasonal timing of the sampling. We excluded patients with decompensated CLD. LS values can be 
influenced by the degree of necroinflammation and the ALT level and can be limited in patients with ascites. ${ }^{44}$ Patients with decompensated CLD have poorer nutritional support and more limited outdoor activity than those with compensated CLD, and both of these factors can affect vitamin D synthesis.

Few clinical studies have evaluated the beneficial effects and adverse toxicities of vitamin D supplementation on hepatic fibrosis. In their experimental model, Abramovich et al. ${ }^{45}$ reported that vitamin D exposure inhibited proliferation of primary hepatic stellate cells and markedly suppressed the expression of collagen. Vitamin D administration also significantly prevented thioacetamide-induced liver fibrosis. Our study had some limitations. First, the cross-sectional nature of this study did not allow for determination of causal relationships between low serum 25(OH)D levels and liver fibrosis. Second, the degree of hepatic fibrosis could not be assessed through liver biopsy. However, we felt that TE could precisely indicate the degree of fibrosis because we could reduce the confounding effects of active inflammation on the LS value by TE examination after liver enzymes had reached a stable state. Third, other potential confounders that may affect serum vitamin D levels, such as the daily duration of exposure to sunlight and dietary status, were not evaluated for each patient.

However, there have been no clinical investigations of vitamin D supplementation in the treatment of human liver fibrosis. In conclusion, the serum 25(OH) D level and LS value obtained by TE in patients with compensated CLD exhibited an inverse linear correlation in this study. Although our study did not allow for determination of a causal relationship between vitamin D deficiency and liver fibrosis, vitamin D deficiency was independently associated with advanced liver fibrosis. Therefore, when clinicians encounter CLD patients with vitamin D deficiency, advanced liver fibrosis should be considered and a tailored follow-up performed. Further longitudinal prospective studies are needed to assess the relationship between vitamin D deficiency and liver fibrosis and to evaluate the effects of vitamin D administration.

\section{CONFLICTS OF INTEREST}

No potential conflict of interest relevant to this article was reported.

\section{ACKNOWLEDGEMENTS}

This work was supported by the Soonchunhyang University Research Fund.

\section{REFERENCES}

1. Holick MF. Vitamin D deficiency. N Engl J Med 2007;357:266281.
2. Stokes CS, Volmer DA, Grünhage F, Lammert F. Vitamin D in chronic liver disease. Liver Int 2013;33:338-352.

3. Putz-Bankuti C, Pilz S, Stojakovic T, et al. Association of 25-hydroxyvitamin D levels with liver dysfunction and mortality in chronic liver disease. Liver Int 2012;32:845-851.

4. Arteh J, Narra S, Nair S. Prevalence of vitamin D deficiency in chronic liver disease. Dig Dis Sci 2010;55:2624-2628.

5. Artaza JN, Norris KC. Vitamin D reduces the expression of collagen and key profibrotic factors by inducing an antifibrotic phenotype in mesenchymal multipotent cells. J Endocrinol 2009;200: 207-221.

6. Beilfuss A, Sowa JP, Sydor S, et al. Vitamin D counteracts fibrogenic TGF-beta signalling in human hepatic stellate cells both receptor-dependently and independently. Gut 2015;64:791-799.

7. Bataller R, Brenner DA. Liver fibrosis. J Clin Invest 2005;115:209218.

8. Rousselet MC, Michalak S, Dupré F, et al. Sources of variability in histological scoring of chronic viral hepatitis. Hepatology 2005;41: 257-264.

9. Castera L, Forns X, Alberti A. Non-invasive evaluation of liver fibrosis using transient elastography. J Hepatol 2008;48:835-847.

10. Kim JH, Kim MN, Han KH, Kim SU. Clinical application of transient elastography in patients with chronic viral hepatitis receiving antiviral treatment. Liver Int 2015;35:1103-1115.

11. Kim SG, Kim YS, Jung SW, et al. The usefulness of transient elastography to diagnose cirrhosis in patients with alcoholic liver disease. Korean J Hepatol 2009;15:42-51.

12. García-Álvarez M, Pineda-Tenor D, Jiménez-Sousa MA, Fernández-Rodríguez A, Guzmán-Fulgencio M, Resino S. Relationship of vitamin D status with advanced liver fibrosis and response to hepatitis C virus therapy: a meta-analysis. Hepatology 2014;60:15411550.

13. Avihingsanon A, Jitmitraparp S, Tangkijvanich P, et al. Advanced liver fibrosis by transient elastography, fibrosis 4 , and alanine aminotransferase/platelet ratio index among Asian hepatitis C with and without human immunodeficiency virus infection: role of vitamin D levels. J Gastroenterol Hepatol 2014;29:1706-1714.

14. Terrier B, Carrat F, Geri G, et al. Low 25-OH vitamin D serum levels correlate with severe fibrosis in HIV-HCV co-infected patients with chronic hepatitis. J Hepatol 2011;55:756-761.

15. Petta $\mathrm{S}$, Cammà $\mathrm{C}$, Scazzone $\mathrm{C}$, et al. Low vitamin $\mathrm{D}$ serum level is related to severe fibrosis and low responsiveness to interferonbased therapy in genotype 1 chronic hepatitis C. Hepatology 2010; 51:1158-1167.

16. Grünhage F, Hochrath K, Krawczyk M, et al. Common genetic variation in vitamin $\mathrm{D}$ metabolism is associated with liver stiffness. Hepatology 2012;56:1883-1891.

17. Efe C, Kav T, Aydin C, et al. Low serum vitamin D levels are associated with severe histological features and poor response to therapy in patients with autoimmune hepatitis. Dig Dis Sci 2014;59: 3035-3042.

18. Suk KT, Baik SK, Yoon JH, et al. Revision and update on clinical 
practice guideline for liver cirrhosis. Korean J Hepatol 2012;18:121.

19. Lin ZH, Xin YN, Dong QJ, et al. Performance of the aspartate aminotransferase-to-platelet ratio index for the staging of hepatitis C-related fibrosis: an updated meta-analysis. Hepatology 2011;53:726-736.

20. Sterling RK, Lissen E, Clumeck N, et al. Development of a simple noninvasive index to predict significant fibrosis in patients with HIV/HCV coinfection. Hepatology 2006;43:1317-1325.

21. Korean Association for the Study of the Liver. KASL Clinical Practice Guidelines: management of chronic hepatitis B. Clin Mol Hepatol 2012;18:109-162.

22. Korean Association for the Study of the Liver (KASL). KASL Clinical Practice Guidelines: management of hepatitis C. Clin Mol Hepatol 2014;20:89-136.

23. Korean Association for the Study of the Liver (KASL). KASL Clinical Practice Guidelines: management of alcoholic liver disease. Clin Mol Hepatol 2013;19:216-254.

24. Korean Association for the Study of the Liver (KASL). KASL Clinical Practice Guidelines: management of nonalcoholic fatty liver disease. Clin Mol Hepatol 2013;19:325-348.

25. Hennes EM, Zeniya M, Czaja AJ, et al. Simplified criteria for the diagnosis of autoimmune hepatitis. Hepatology 2008;48:169-176.

26. Prevention and management of osteoporosis. World Health Organ Tech Rep Ser 2003;921:1-164.

27. Sandrin L, Fourquet B, Hasquenoph JM, et al. Transient elastography: a new noninvasive method for assessment of hepatic fibrosis. Ultrasound Med Biol 2003;29:1705-1713.

28. Ford ES, Ajani UA, McGuire LC, Liu S. Concentrations of serum vitamin D and the metabolic syndrome among U.S. adults. Diabetes Care 2005;28:1228-1230.

29. Liu E, Meigs JB, Pittas AG, et al. Plasma 25-hydroxyvitamin d is associated with markers of the insulin resistant phenotype in nondiabetic adults. J Nutr 2009;139:329-334.

30. Rode A, Fourlanos S, Nicoll A. Oral vitamin D replacement is effective in chronic liver disease. Gastroenterol Clin Biol 2010;34: 618-620.

31. Arao M, Murase K, Kusakabe A, et al. Prevalence of diabetes mellitus in Japanese patients infected chronically with hepatitis C virus. J Gastroenterol 2003;38:355-360.

32. Li WD, Fu KF, Li GM, et al. Comparison of effects of obesity and non-alcoholic fatty liver disease on incidence of type 2 diabetes mellitus. World J Gastroenterol 2015;21:9607-9613.
33. Yu R, Sun J, Zheng Z, et al. Association between vitamin D level and viral load or fibrosis stage in chronic hepatitis B patients from Southern China. J Gastroenterol Hepatol 2015;30:566-574.

34. Hsiang JC, Gane EJ, Bai WW, Gerred SJ. Type 2 diabetes: a risk factor for liver mortality and complications in hepatitis B cirrhosis patients. J Gastroenterol Hepatol 2015;30:591-599.

35. Kuo YH, Lu SN, Chen CH, et al. The changes of liver stiffness and its associated factors for chronic hepatitis B patients with entecavir therapy. PLoS One 2014;9:e93160.

36. Wai CT, Greenson JK, Fontana RJ, et al. A simple noninvasive index can predict both significant fibrosis and cirrhosis in patients with chronic hepatitis C. Hepatology 2003;38:518-526.

37. Kim BK, Kim do Y, Park JY, et al. Validation of FIB-4 and comparison with other simple noninvasive indices for predicting liver fibrosis and cirrhosis in hepatitis B virus-infected patients. Liver Int 2010;30:546-553.

38. Castéra L, Vergniol J, Foucher J, et al. Prospective comparison of transient elastography, Fibrotest, APRI, and liver biopsy for the assessment of fibrosis in chronic hepatitis C. Gastroenterology 2005;128:343-350.

39. Bae RC, Cho HJ, Oh JT, et al. Clinical factors influencing liver stiffness as measured by transient elastography (Fibroscan) in patients with chronic liver disease. Korean J Hepatol 2010;16:123-130.

40. Kim do Y, Kim SU, Ahn SH, et al. Usefulness of FibroScan for detection of early compensated liver cirrhosis in chronic hepatitis B. Dig Dis Sci 2009;54:1758-1763.

41. Kim SU, Han KH, Ahn SH. Non-invasive assessment of liver fibrosis: time to move from cross-sectional studies to longitudinal ones. J Gastroenterol Hepatol 2010;25:1472-1473.

42. Lee HW, Yoo EJ, Kim BK, et al. Prediction of development of liverrelated events by transient elastography in hepatitis B patients with complete virological response on antiviral therapy. Am J Gastroenterol 2014;109:1241-1249.

43. Wicherts IS, Boeke AJ, van der Meer IM, van Schoor NM, Knol DL, Lips P. Sunlight exposure or vitamin D supplementation for vitamin D-deficient non-western immigrants: a randomized clinical trial. Osteoporos Int 2011;22:873-882.

44. Jung KS, Kim SU. Clinical applications of transient elastography. Clin Mol Hepatol 2012;18:163-173.

45. Abramovitch S, Dahan-Bachar L, Sharvit E, et al. Vitamin D inhibits proliferation and profibrotic marker expression in hepatic stellate cells and decreases thioacetamide-induced liver fibrosis in rats. Gut 2011;60:1728-1737. 